\title{
EFFECTS OF COASTAL VEGETATION SPECIES AND GROUND SLOPE ON STORM SURGE DISASTER MITIGATION
}

\author{
Shamal Chandra Das, ${ }^{1}$ Kosuke Iimura ${ }^{2}$ and Norio Tanaka ${ }^{1}$
}

\begin{abstract}
The coastline of Bangladesh is mostly exposed to extreme meteorological and hydrological conditions where cyclones and storm surges cause devastating effects including loss of human lives and destruction of properties. Coastal vegetation has been considered as a low-cost and natural protection to reduce the energy of current and surge. Present study explored the effectiveness of coastal vegetation against cyclonic storm surge based on species composition, forest width and near-shore run-up slope revealed by field investigations and numerical simulations. A calibrated hydrodynamic numerical model based on modified one-dimensional depth-averaged non-linear long wave differential equations was used to simulate the storm surge mitigation effected by the coastal vegetation. Considering two different types of coastal species, mangrove species, Rhizophora apiculata and beach species, Casuarina equisetifolia, numerical simulations were conducted to assess the effect of coastal forest on the storm surge mitigation. This analysis showed that double layers of wide vegetation belt $(300 \mathrm{~m})$ in the vertical direction with $R$. apiculata and C. equisetifolia on mild slope (1:500) exhibited a strong potential to decrease surge wave height and velocity. However, water depth reduction was low compared with flow velocity reduction. The maximum water depth and current velocity reduced to $1.4 \mathrm{~m}(22 \%$ reduction) and $1.2 \mathrm{~m} / \mathrm{s}$ ( $49 \%$ reduction), respectively, behind the vegetation in comparison with the case without vegetation. Wide coastal vegetation belt with mild slope might be suitable for storm surge energy reduction; however, a doubling or tripling of forest width (from $100 \mathrm{~m}$ to $200 \mathrm{~m}$ or $300 \mathrm{~m}$ ) did not produce two-fold or three-fold increase of wave reduction with negligible additional velocity reduction. For the same vegetation density the wave energy reduction by $R$. apiculata was not increased significantly compared to the C. equisetifolia. But young densely C. equisetifolia found more effective to reduce storm surge energy. The information would be of value to policy and decision makers for coastal landscape planning, rehabilitation and coastal resource management.
\end{abstract}

Keywords: Rhizophora apiculata; Casuarina equisetifolia; Cyclonic storm surge; Wave energy

\section{INTRODUCTION}

Bangladesh is one of the most densely populated countries in the world where $28 \%$ of the population living in the coastal area. Bangladesh, with its repeated cycle of floods, cyclones, and storm surges, has proved to be one of the most disaster-prone areas of the world. Cyclones and storm surges are common phenomena and cause devastating effects to the country including loss of human lives and destruction of properties (Paul 2009). Due to the peculiar topography (i.e., triangular or V-shaped basin), shallowness of the water body, together with a large tidal range make the storm surges on the Bay of Bengal coast more dangerous than any other region of the globe and approximate percentage of storm surge impact in Bangladesh is 40 compared with global perspective (Murty and Neralla 1992).

There are opinions about the effectiveness and ineffectiveness of coastal forest (Shuto 1987). Affirmative views assert that a forest is effective because it stops driftwood and other floating debris. It reduces water flow velocity and inundation water depth behind the forest. It also provides a live-saving means by catching persons carried out off by storm surges. But on the other hand, a represent negative opinion is that a forest may be ineffective against a catastrophic event, and at worst, trees themselves could become destructive forces to surrounding houses and hurt people, if cut down by storm surges. Also there any exist of an open gap in a forest (i.e., a road, river, etc.) can channel and amplify a strong current by forcing it into the gap (Thuy et al. 2009). However, many studies have revealed that these demerits can be overcome with proper planning and management of coastal forest (Tanaka 2009).

The role of coastal forest in the mitigation of disasters like tsunamis, cyclones unexpectedly became a hotly debated topic in the aftermath of the 2004 Indian Ocean tsunami and the cyclone Sidr2007 in Bangladesh and many research initiatives have been in progress since then, aimed at assessing the role of bio-shields in disaster impact mitigation. A number of hydrodynamic numerical models have been developed for storm surge generation and propagation and able to simulate the extent of inundation but the effect of coastal vegetation on the cyclone surge levels are limited (Mazda et al. 2006). Field investigation after cyclone Sidr2007 revealed that coastal vegetation served as buffer zone and reduced the effects of Sidr behind vegetation. Even though the degree of their effectiveness

${ }^{1}$ Institute for Environmental Science and Technology, Graduate School of Science and Engineering, Saitama University, 255 Shimo-okubo, Sakura-ku, Saitama-shi, Saitama, 338-8570, Japan

${ }^{2}$ Graduate Student, Hydraulic and Environmental Engineering Laboratory, 255 Shimo-okubo, Sakura-ku, Saitamashi, Saitama, 338-8570, Japan 
depends on many parameters including forest width, tree density, tree diameter, tree height, species composition, ground elevation and near-shore run-up slope etc., these parameters were not evaluated systematically to identify their potential for cyclone-induced storm surge protection. Therefore, the objectives of this study are to explore the effectiveness of coastal vegetation against cyclonic storm surge based on species composition, forest width and near-shore run-up slope revealed by field investigation and numerical simulations and future establishment and management of effective vegetation bioshield for extreme events hazard protection.

\section{MATERIAL AND METHODS}

Mathematical background

The coastal vegetation effect for reducing storm surge current was analyzed by using modified onedimensional depth-averaged non-linear long wave differential equations. One dimensional equations are written as follows.

Continuity equation:

$$
\frac{\partial \zeta}{\partial t}+\frac{\partial Q}{\partial x}=0
$$

Momentum equation:

$$
\frac{\partial Q}{\partial t}+\frac{\partial}{\partial x}\left(\frac{Q^{2}}{d}\right)+g d \frac{\partial \zeta}{\partial x}+\frac{\tau_{b}}{\rho_{w}}-\frac{\tau_{s}}{\rho_{w}}+\frac{f}{\rho_{w}}=0
$$

where $Q$ : discharge in unit width, $d$ : total water depth, $\zeta$ : water depth from the sea level, $g$ : gravitational acceleration, $\rho_{w}$ : the density of sea water, $\tau_{b}$ : bed shear stress, $\tau_{s}$ : shear stress at sea water surface, $f$ : drag force by vegetation in unit area.

Bed shear stress, $\tau_{b}$ is evaluated as:

$$
\tau_{b}=\frac{\rho_{w} g n^{2}}{d^{7 / 3}} Q|Q|
$$

where $n$ is the Manning roughness coefficient $(=0.025$ in this study, referring to Harada and Imamura 2006).

Shear stress at sea water surface, $\tau_{s}$ is analyzed by:

$$
\tau_{s}=\rho_{a} \gamma_{a}^{2} W|W|
$$

where $\rho_{a}$ : density of air $\left(1.2 \mathrm{~kg} / \mathrm{m}^{3}\right), \gamma_{a}$ : non-dimensional friction coefficient at sea surface $\left(\gamma_{a}{ }^{2}=0.0026\right.$ in this study), $W$ : wind velocity $(=60 \mathrm{~m} / \mathrm{s}$ outside the vegetation and $0 \mathrm{~m} / \mathrm{s}$ inside the vegetation in this study). The numerical model was updated by including $\tau_{s}$ term on the model. The water surface increase by the wind shear was almost the same with the value calculated by the Colding equation (Ministry of transport, Japan 1966).

Drag force by vegetation in unit area is applied below (Tanimoto et al. 2007):

$$
f=\gamma \frac{1}{2} \rho_{w} C_{D-a l l} b_{r e f} \frac{Q|Q|}{d}
$$

where $C_{D-\text { all }}$ is the drag coefficient that includes the tree vertical structure (Tanaka et al. 2007), $b_{r e f}$ : tree trunk diameter at breast height, $\gamma$ : number of trees in unit area.

$C_{D-a l l}$ is proposed by Tanaka et al. (2007) as below:

$$
\begin{aligned}
& C_{D-a l l}=C_{D-r e f} \frac{1}{d} \int_{0}^{d} \frac{b(z)}{b_{r e f}} \frac{C_{D}(z)}{C_{D-r e f}} d z=C_{D-r e f} \frac{1}{d} \int_{0}^{d} \alpha(z) \beta(z) d z \\
& \alpha(z)=\frac{b(z)}{b_{r e f}}
\end{aligned}
$$




$$
\beta(z)=\frac{C_{D}(z)}{C_{D \text { ref }}}
$$

where $C_{D-\text {-ref }}$, reference drag coefficient ( $=1$ considering a circular cylinder in this study), $C_{d}(z), b(z)$ $=$ drag coefficient, cumulative width of tree trunks and branches $(\mathrm{m})$ at height $z$, respectively, $\alpha(z)=$ additional coefficient for expressing the vertical tree structure, $\beta(z)=$ additional coefficient for representing the effect of leaves and the inclination of branches. For the value of $\beta(z)$, previous research indicates that the additional drag by leaves itself can be assumed a constant value $(=1.25$ in this study (Tanaka et al. 2007)).

\section{Numerical Model validation}

Since the existing data are not accurate enough for model validation, the numerical model was validated through a limited experimental study. The laboratory experiments for long waves were carried out in a wave channel of $0.4 \mathrm{~m}$ wide, $0.75 \mathrm{~m}$ in height and $18 \mathrm{~m}$ long at Saitama University. Figure 1(b) shows the details of the vegetation model that is fixed on a bed slope in a flume. The model bed consisted of two relatively steep slopes, starting from $1: 4.7$ spanning $0.76 \mathrm{~m}$ and then connected to a 1:20.5 slope which has a length of $7.01 \mathrm{~m}$. The effective horizontal length of the model bed was $14.27 \mathrm{~m}$ of the total flume length of $18 \mathrm{~m}$. Vegetation (trees) was represented by wooden cylindrical rods with a diameter of $5 \mathrm{~mm}$ mounted in a staggered arrangement (Fig. 1(a)). The water depth in front of the wave paddle was $0.44 \mathrm{~m}$. An electric wave generator was used to synthesize sinusoidal long waves at a period of 20s. A range of wave gauges, out of which two were in front of and behind the vegetation model, was deployed to measure temporal variation of water surface elevations. Firstly the numerical model was calibrated with the case without vegetation model and Manning's roughness coefficient was found to be 0.025 for the bed slope. In turn, the numerical model was validated with the case with vegetation model and drag coefficient for the vegetation was about 1.5. Inertia effect was negligible. For more detail, please refer Tanaka et al. (2009).
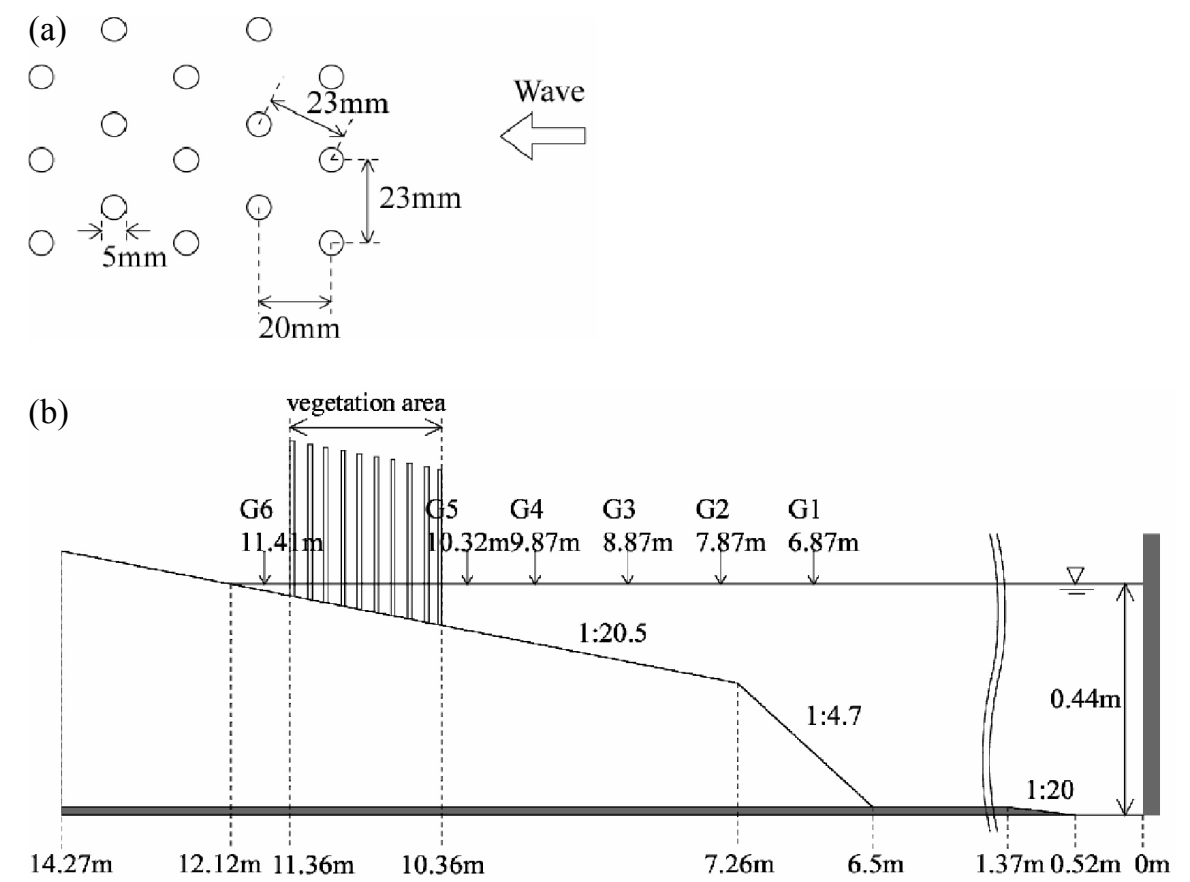

Figure 1. Wave channel experiment (a) details of vegetation model and (b) experimental setup

\section{Vegetation conditions, topography and storm surge conditions}

Post tsunami field investigation demonstrated that two layers of vegetation in the vertical direction with Pandanus odoratissimus and Casuarina equisetifolia can impose a considerable buffer against extreme oceanographic events (Tanaka et al. 2007). Mangrove species, 'Rhizophora apiculata' (here after called Rhizophora species) with a complex aerial root structure that provides additional value of drag coefficient and beach species, 'Casuarina equisetifolia' (here after called Casuarina species) that 
grows on sandy beaches and provides trapping effect, were selected for simulations in this study (as shown in Fig. 2a). The tree conditions like reference tree diameter, tree height, aerial root height, tree density etc. are kept constants for respective species based on field investigation after Sidr2007 in Bangladesh and literature survey (Tanaka et al. 2007). For Rhizophora species, the average tree height is $8.0 \mathrm{~m}$, aerial root height is $2.25 \mathrm{~m}$, reference diameter of the tree trunk, $b_{\text {ref }}$ is $0.18 \mathrm{~m}$, and density, the number of trees per unit area, $\mathrm{m}$ is 0.104 . For Casuarina species, the average tree height is $10.0 \mathrm{~m}, b_{\text {ref }}$ is $0.16 \mathrm{~m}$ and $\mathrm{m}$ is 0.36 . Figure $2 \mathrm{~b}$ shows the vertical distribution of drag characteristics of the two species (modified from Tanaka et al. (2007)). The difference becomes clearer as the Rhizophora species has complex aerial root structures that affect the drag coefficient compared with Casuarina. The value of drag coefficient $\left(C_{D \text {-all }}\right)$ that includes the tree vertical structure was close to the value obtained for mangrove trees (Tanaka et al. 2009).

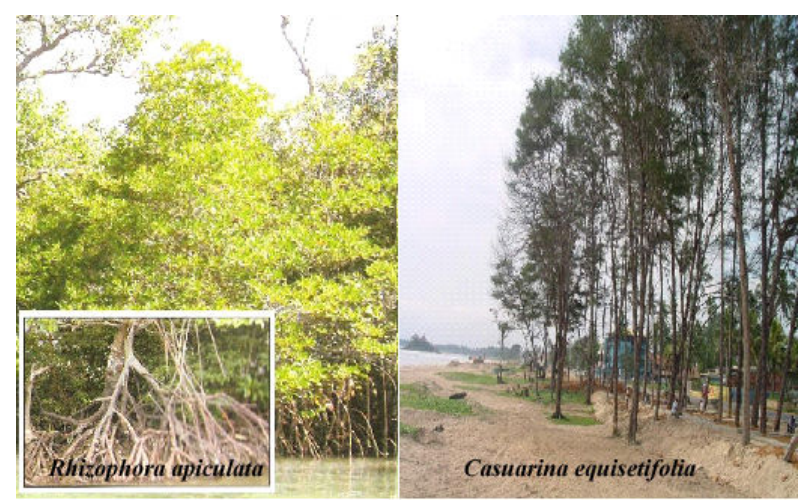

(a)

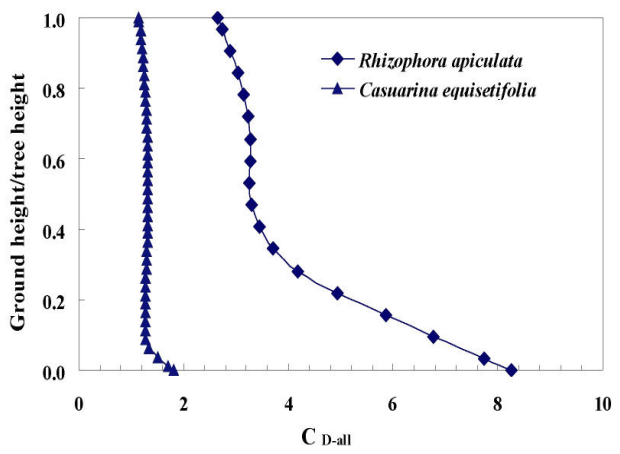

(b)

Figure 2. (a) vertical configuration and (b) drag characteristics of $R$. apiculata and $C$. equisetifolia (modified from Tanaka et al. (2007))

A uniform coastal topography with a straight shoreline with the cross section perpendicular (x-axis) to the shoreline, as shown in Fig. 3, was selected as a test case. The water depth is $200 \mathrm{~m}$ at the wave generation boundary. It continues for $1000 \mathrm{~m}$ treated as linear zone and is connected to a 1:10 slope that spans $1000 \mathrm{~m}$ treated as transition zone and again to a 1:200 slope treated as nonlinear zone that spans $20,000 \mathrm{~m}$ until it meets the shoreline. The rear boundary of the vegetation belt is changed with changing belt thickness. The simulation conditions are set with the following cases: Case 1: double layers of vegetation in the vertical direction (Rhizophora apiculata up to the offshore edge and Casuarina equisetifolia starts from offshore edge) considering three ground slopes, 1:100 (typical), 1:250 (moderately mild), and 1:500 (mild) with three vegetation belts, 100m (Rhizophora 50m and Casuarina $50 \mathrm{~m}$ ) (narrow), 200m (Rhizophora $100 \mathrm{~m}$ and Casuarina $100 \mathrm{~m}$ ) (moderately wide) and $300 \mathrm{~m}$ (Rhizophora 150m and Casuarina 150m) (wide); Case 2: single layer of vegetation (R. apiculata and $C$. equisetifolia set individually) considering mild slope (1:500) with wide vegetation belt (300m). Case 2 was selected to evaluate the contribution of individual species in comparison with double layers (case 1).

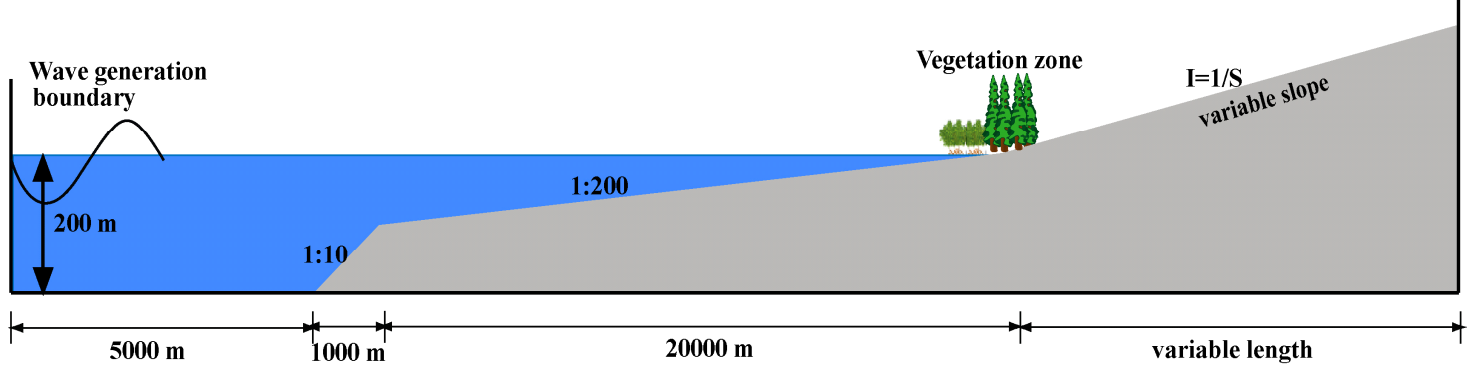

Figure 3. Approximate geological and vegetation condition of coastal topography for numerical simulation 
Sinusoidal wave height $(3.5 \mathrm{~m})$ at the wave generation boundary for 2 hours long wave and 2 minutes wave as a representative of shortwave with wind velocity $60 \mathrm{~m} / \mathrm{s}$ were selected so that the maximum water level at coast becomes similar of that observed at cyclone Sidr2007 in Bangladesh. Vegetation effects on storm surge were analyzed considering two mechanisms as; 1) decrement of the water depth by reducing the wind friction inside the vegetation compared with the non-vegetation case, 2) drag effect by vegetation. Figure 3 shows the schematic sketch of the geological condition with plantation area. Water depth and flow velocity change in the time scale were obtained in front of, middle of, and behind the vegetation for different cases (case 1 and case 2) as explained above.

\section{RESULTS AND DISCUSSION}

A relationship is defined to understand the effectiveness of coastal vegetation to hamper the storm surge energy to compare simulation results:

$$
\text { Percentage reduction }(P R) \text { of max. value }=\frac{\text { Max. value WOV }- \text { Max. value WV }}{\text { Max. value WOV }} \times 100 \%
$$

where WOV: without vegetation and WV: with vegetation. This ratio reflects a decrement in a hydraulic property by a positive percentage and an increment in a hydraulic property by a negative percentage due to the vegetation effect. Different combinations (changing ground slopes and vegetation widths) were analyzed to explore the vegetation effect to dissipate cyclone-induced storm surge energy.

\section{Percentage reduction of maximum water depth (case 1: double layers of vegetation)}

The reduction of the water depth in the middle of and behind the vegetation for the $100 \mathrm{~m}$ vegetation belt on the 1:100, 1:250 and 1:500 ground slopes was negligible in comparison with the case without vegetation. This indicates that the capacity of vegetation to reduce the water depth is minimal for the narrow vegetation belt $(100 \mathrm{~m})$. However, when the ground slope gradually decreases, the reduction in water depth in the middle of and behind the vegetation belt is increased especially for the mild slope (1:500). Percentages of the maximum water depth reduction in the middle of and behind the $100 \mathrm{~m}$ vegetation belt were $3.8 \%$ and $4.3 \%, 5.6 \%$ and $6.4 \%, 10.3 \%$ and $11.0 \%$ for $1: 100,1: 250$, and 1:500 ground slopes, respectively (Table 1). Depth reduction also found low for the $200 \mathrm{~m}$ vegetation belt on the 1:100 and 1:250 ground slopes and $300 \mathrm{~m}$ vegetation belt on the 1:100 ground slope. Percentage of the maximum storm surge height reduction was found $17.3 \%$ and $21.7 \%$ behind the vegetation on the 1:500 ground slope for both $200 \mathrm{~m}$ and $300 \mathrm{~m}$ vegetation belts, respectively. In addition, it is clear that widening the vegetation belt definitely increased the reduction of the maximum water depth behind the vegetation belt (Table 1). The maximum water depth is increased in front of the vegetation in comparison with the case without vegetation due to drag effect by the vegetation, which is inferred from the wave reflection. But this phenomenon was absent in our cases. Nandasena et al. (2009) also investigated the effect of coastal vegetation for reducing the tsunami energy by numerical model and laboratory experiment and found that the maximum water depth in front of the vegetation belt is slightly less than that in case of without vegetation in spite of the wave reflection. They explained the phenomena as a combined effect of the relatively steep slope and densely growing vegetation.

A maximum decrease in surge of $1.37 \mathrm{~m}$ for the $300 \mathrm{~m}$ vegetation belt was found compared to the decrement value of $1.09 \mathrm{~m}$ and $0.71 \mathrm{~m}$ with $200 \mathrm{~m}$ and $100 \mathrm{~m}$ vegetation belts, respectively behind the vegetation on the 1:500 ground slope in comparison with the case without vegetation (Fig. 4). Water depth reduction for 1:100 ground slope was found negligible compared with 1:200 and 1:500 ground slopes for different vegetation belts since steep slope have high gravity reduction rate compared with mild slope (Nandasena et al. 2009). This result gives the importance of forest width to reduce the storm surge energy although the value depends on many other factors like cyclone intensity, storm surge height, storm tide levels and the spectral characteristics of the incident waves and location of the forests (FAO 2007). Kabir et al. (2006) in Bangladesh carried out a modelling study to assess the impact of afforestation on cyclone surge level considering 1970 cyclone for simulation and found a maximum reduction of storm surge height $0.45 \mathrm{~m}$ with $600 \mathrm{~m}$ strip of mangroves (Rhizophora $\mathrm{sp}$.). Storm surge height of 1970 cyclone was significantly higher (10.6m) compared with storm surge height of Sidr2007 (6.0m) in Bangladesh (Karim and Mimura 2008). 


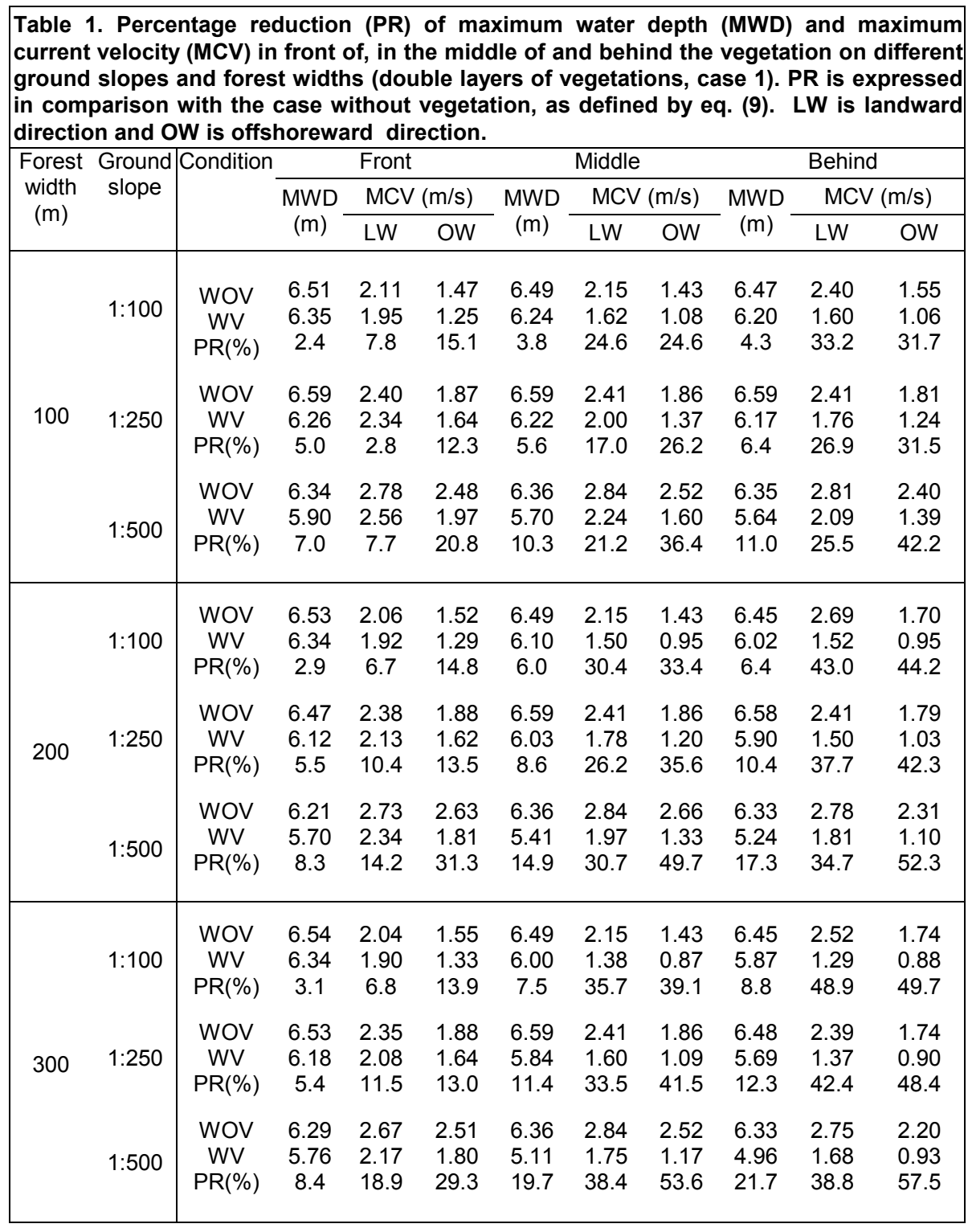

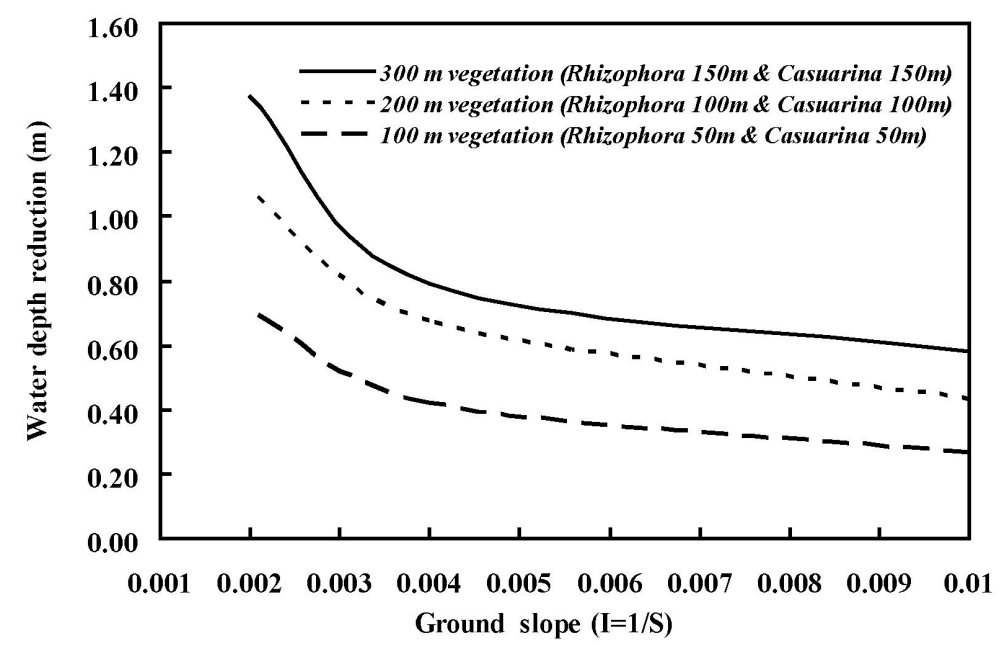

Figure 4. Variation of water depth reduction behind the forest with different ground slopes and forest widths (case 1: double layers of vegetation) 


\section{Percentage reduction of maximum current velocity (case 1: double layers of vegetation)}

The percentage reduction of the maximum current velocity both in the landward and shoreward directions was higher than the maximum water depth reduction both in the middle of and behind the vegetation belts irrespective of the ground slope and the width of the vegetation belt (Table 1). This demonstrates that current velocity reduction is dominant compared with the water depth. Increasing ground slope amplified the current velocity reduction in the landward direction behind the vegetation which is the opposite of the maximum water depth reduction trend. For the $100 \mathrm{~m}$ vegetation belt, the maximum current velocity reductions (landward direction) were $24.6 \%, 17.0 \%$, and 21.2\% for 1:100, $1: 250$, and 1:500 ground slopes, respectively in the middle of the vegetation and $33.2 \%, 26.9 \%$, and $25.5 \%$ behind the vegetation (Table 1). This value of reduction gradually increased with increasing forest width and extremely reduced value (48.9\%) was observed on the 1:100 ground slope behind the vegetation with $300 \mathrm{~m}$ vegetation belt. The maximum current velocity reduced in the shoreward direction also shows similar trend to reduction of the forward current velocity, but a little higher due to blocking and resistance by the vegetation and the maximum current velocity in the shoreward direction was extremely reduced $(57.5 \%)$ behind the vegetation belt on the very mild slope $(1: 500)$ for the $300 \mathrm{~m}$ vegetation belt.

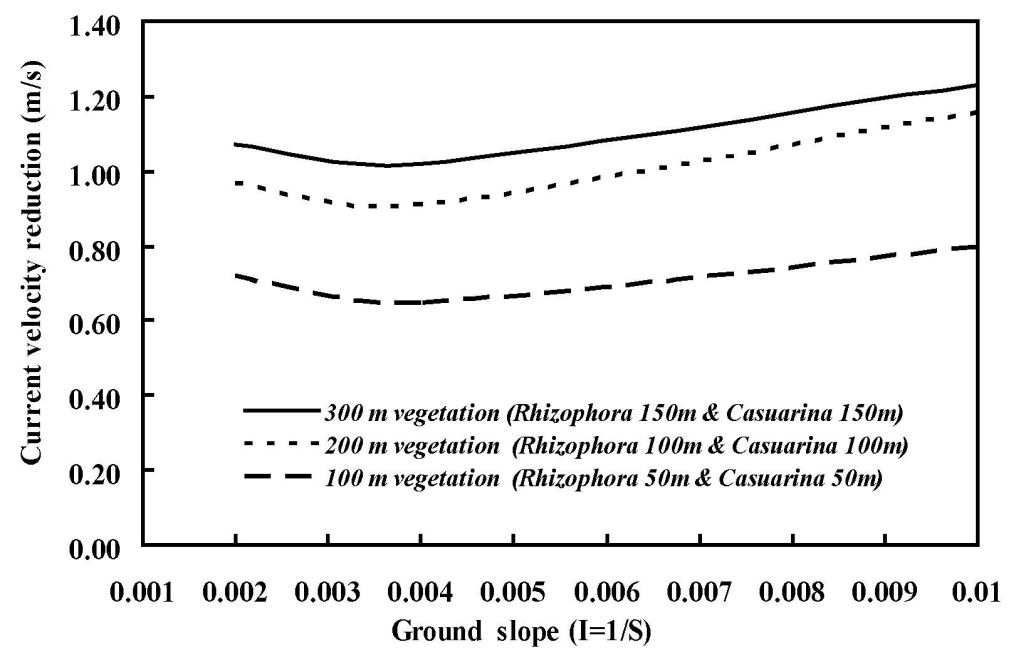

Figure 5. Variation of current velocity reduction rate behind forest with different ground slopes and forest widths (case 1: double layers of vegetation)

The difference of flow variation (behind vegetation) with $200 \mathrm{~m}$ and $300 \mathrm{~m}$ vegetation belts on the different ground slopes was significant compared with $100 \mathrm{~m}$ vegetation belt in comparison with the case without vegetation and steep ground slope amplified current velocity reduction compared with mild slope with the same vegetation belt (Fig. 5). The maximum velocity reduction was found $1.23 \mathrm{~m} / \mathrm{s}$ and $1.07 \mathrm{~m} / \mathrm{s}$ for the $300 \mathrm{~m}$ vegetation belt on the 1:100 and 1:500 ground slopes respectively, behind the vegetation. Where as, the maximum decrease of surge height was found $0.58 \mathrm{~m}$ and $1.37 \mathrm{~m}$ for the same vegetation width on the 1:100 and 1:500 slopes respectively, behind the vegetation (Fig. 4). This confirmed that densely grown wide coastal vegetation on the mild ground slope dissipates surge energy more efficiently than the same vegetation on the steep ground slope. Results also show that for the mild slope (1:500), a doubling or tripling of forest width (from $100 \mathrm{~m}$ to $200 \mathrm{~m}$ or $300 \mathrm{~m}$ ) did not produce two-fold or three-fold increase of water depth reduction but lowers it $17.3 \%$ for $200 \mathrm{~m}$ vegetation and $21.7 \%$ for $300 \mathrm{~m}$ vegetation compared with $11 \%$ for $100 \mathrm{~m}$ vegetation with negligible additional velocity reduction (Table 1 ).

The interesting location in the study is the area behind vegetation where water depth and current velocity were extremely reduced by the vegetation to provide a favorable environment for the protection of inhabitants and the infrastructures in an extreme event hazard like tsunami or storm surge. Many inhabitants told the situation of storm surge during Sidr2007 in Bangladesh and they climbed on the trees to survive (JSCE Sidr2007 investigation team 2008). The Sumatra tsunami that occurred on 26 December 2004 destroyed many coastal areas around the Indian Ocean. However, some coastal forests acted as a buffer and protected human lives behind the forests (Danielsen et al. 2005). 


\section{Percentage reduction of maximum water depth and maximum current velocity (case 2: single layer of vegetation)}

The effectiveness of double layers of vegetation in the vertical direction with Rhizophora apiculata and Casuarina equisetifolia on the storm surge mitigation has been discussed in the above paragraphs and exhibited a strong potential to reduce the maximum water depth and current velocity behind the vegetation especially in case of wide vegetation belt and mild slope. But in the case of double layers of vegetation it is difficult to find out the contribution of individual species since during storm surge wave attacks mainly the frontal strips.

Subsequently, we analyzed each species, $R$. apiculata and C. equisetifolia separately for the $300 \mathrm{~m}$ vegetation belt on the mild ground slope (1:500) to evaluate the contribution of individual species in comparison with double layers of vegetation in the vertical direction. Table 2 shows that the reduction of water depth and current velocity for case 2 (single layer of vegetation) is more or less same. Although the drag resistance of $R$. apiculata is higher than the $C$. equisetifolia but our study found higher wave height reduction behind vegetation by $C$. equisetifolia (23.4\%) compared with $R$. apiculata $(18.9 \%)$ for the same vegetation belt $(300 \mathrm{~m})$ and ground slope $(1: 500)$. This might be the effect of density differences as mentioned above (materials and methods' section).

\begin{tabular}{|c|c|c|c|c|c|c|c|c|c|c|c|c|}
\hline \multirow{3}{*}{\begin{tabular}{|c}
$\begin{array}{c}\text { Forest } \\
\text { width } \\
\text { (m) }\end{array}$ \\
\end{tabular}} & \multirow[t]{3}{*}{ Species } & \multirow{3}{*}{$\begin{array}{c}\text { Ground } \\
\text { slope }\end{array}$} & \multirow{3}{*}{ Condition } & \multicolumn{3}{|c|}{ Front } & \multicolumn{3}{|c|}{ Middle } & \multicolumn{3}{|c|}{ Behind } \\
\hline & & & & \multirow{2}{*}{$\begin{array}{l}\text { MWD } \\
(\mathrm{m})\end{array}$} & \multicolumn{2}{|c|}{ MWD (m) } & \multirow{2}{*}{$\begin{array}{l}\text { MWD } \\
(\mathrm{m})\end{array}$} & \multicolumn{2}{|c|}{$\mathrm{MCV}(\mathrm{m} / \mathrm{s})$} & \multirow{2}{*}{$\begin{array}{l}\text { MWD } \\
(\mathrm{m})\end{array}$} & \multicolumn{2}{|c|}{$\operatorname{MCV}(\mathrm{m} / \mathrm{s})$} \\
\hline & & & & & LW & LW & & LW & OW & & LW & OW \\
\hline 300 & $\begin{array}{c}R . \\
\text { apiculata }\end{array}$ & $1: 500$ & $\begin{array}{c}\text { WOV } \\
\text { WV } \\
\text { PR(\%) }\end{array}$ & $\begin{array}{c}6.28 \\
5.74 \\
8.7\end{array}$ & $\begin{array}{l}2.43 \\
2.17 \\
13.8\end{array}$ & $\begin{array}{l}2.51 \\
1.81 \\
25.6\end{array}$ & $\begin{array}{l}6.35 \\
5.30 \\
16.6\end{array}$ & $\begin{array}{l}2.70 \\
1.72 \\
36.2\end{array}$ & $\begin{array}{l}2.46 \\
1.22 \\
50.4\end{array}$ & $\begin{array}{l}6.36 \\
5.15 \\
18.9\end{array}$ & $\begin{array}{l}2.84 \\
1.75 \\
38.4\end{array}$ & $\begin{array}{l}2.52 \\
1.13 \\
55.1\end{array}$ \\
\hline 300 & $\begin{array}{c}\text { C. } \\
\text { equisetifolia }\end{array}$ & $1: 500$ & $\begin{array}{c}\text { WOV } \\
\text { WV } \\
\text { PR(\%) }\end{array}$ & $\begin{array}{c}6.36 \\
5.76 \\
9.4\end{array}$ & $\begin{array}{l}2.84 \\
2.23 \\
21.5\end{array}$ & $\begin{array}{l}2.51 \\
1.74 \\
31.0\end{array}$ & $\begin{array}{l}6.33 \\
5.00 \\
21.0\end{array}$ & $\begin{array}{l}2.72 \\
1.54 \\
43.3\end{array}$ & $\begin{array}{l}2.16 \\
0.97 \\
54.9\end{array}$ & $\begin{array}{l}6.32 \\
4.85 \\
23.4\end{array}$ & $\begin{array}{l}2.67 \\
1.68 \\
37.1\end{array}$ & $\begin{array}{l}2.02 \\
0.84 \\
58.1\end{array}$ \\
\hline
\end{tabular}

Finally, we analyzed case 1 and case 2 considering three different densities. The values of the vegetation densities (the number of trees per unit area), $\mathrm{m}=0.360,0.232$, and 0.104 were used in the computation and compared with previous results (Fig. 6). The results show that R. apiculata was effective to reduce both water depth and current velocity compared with $C$. equisetifolia due to their complex aerial root structure. Field experience after Indian Ocean tsunami also observed similar phenomena (Tanaka et al. 2007). However, the water depth and current velocity reduction by $R$. apiculata found proportionately small compared with drag characteristics of the two species, $R$. apiculata and C. equisetifolia (Fig. 2b). This might be the effect of large storm surge height. At the shallow water level the effect of the drag force of aerial roots of Rhizophora species on the wave reduction increases but with the increase of water level, resulting in a huge decrease in the rate of wave reduction (Mazda et al. 2006) and another point is that Rhizophora species exhibit the greatest drag resistance, especially within the lower strata (Tanaka et al. 2007). Variation of vertical drag resistance at different height in fig 2(b) also supports this statement.

The obstruction density caused by the mangrove wood structure decreases rapidly with height and therefore, as the water level increases because of the storm surge there is propositionally less flow resistance and less reduction of wave energy. Yanagisawa et al. (2009) also reported on their study on the reduction effects of mangrove forest on a tsunami based on filed and laboratory experiments that the reduction effect of tsunami inundation depth decreased when the tsunami inundation depth exceeded $3 \mathrm{~m}$, and was most lost when the tsunami inundation depth exceeded $6 \mathrm{~m}$. On the other hand, Tanaka et al. (2007) reported that young densely $C$. equisetifolia (diameter, $d=0.15 \mathrm{~m}$ ) is more effective to reduce energy of extreme events. Danielsen et al. (2005) also reported in the 'Asian Tsunami: a protective role for coastal vegetation' that the areas with coastal tree vegetation (mangrove and Casuarina plantation) were less damaged than areas without, based on satellite images. Field investigations along the coast of Tamil Nadu seaside after the tsunami of December 2004 revealed that Casuarina forests performed remarkably as absorbers of energy from violent waves and uprooting of trees was exclusively restricted 
to a frontal strip ranging from $5 \mathrm{~m}$ to $25 \mathrm{~m}$ nearest to the shore where the maximum wave run-up was $6.5 \mathrm{~m}$ above the sea level (Mascarenhas and Jayakumar 2008).
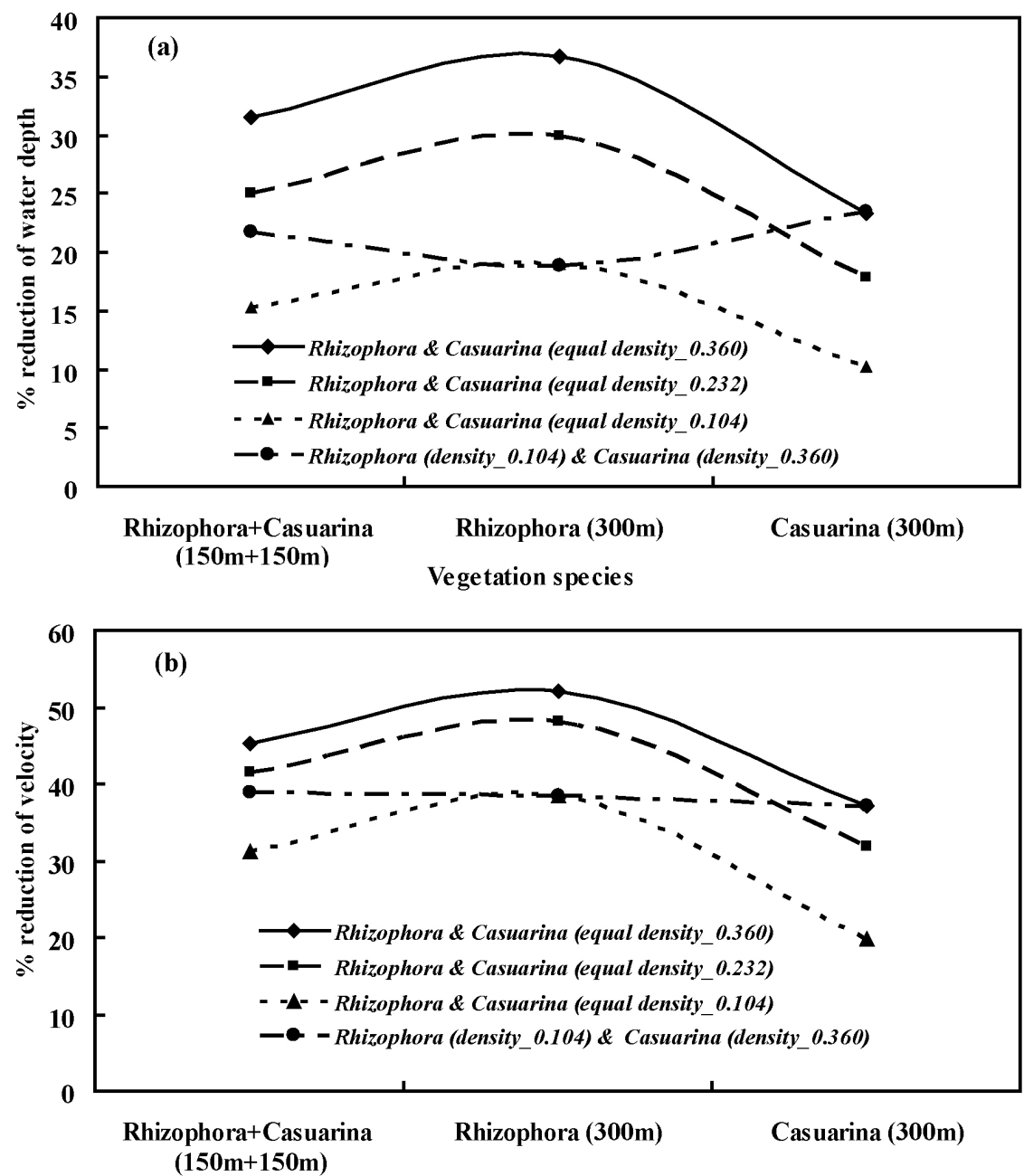

Vegetation species

Figure 6. Comparison of percentage reduction of (a) water depth and (b) current velocity with vegetation species and densities

According to the local people speech, the water depth decrement at the place behind the coastal vegetation with $150 \mathrm{~m}$ width at Mathbaria along Baleswar river during Sidr2007 in Bangladesh was confirmed $0.5-1.0 \mathrm{~m}$ compared with the water depth at the front of the coastal vegetation (JSCE Sidr2007 investigation team 2008). Further, there are several evidences in favour of coastal vegetation for extreme events hazard protection. The tree vegetation reduces wave amplitude and energy, as proved by the measurements of wave forces and modelling of fluid dynamics (Massel et al. 1999). Analytical model shows that 30 trees per $100 \mathrm{~m}^{2}$ in a $100 \mathrm{~m}$ wide belt may reduce the maximum tsunami flow pressure by more than $90 \%$ (Hiraishi and Harada 2003). Moreover, the additional benefits of the coastal vegetations include protection from coastal erosion and preservation of wetlands. There was a 20 to $30 \%$ reduction in repair and maintenance costs of sea dykes due to the presence of coastal forest in front of the dyke (FAO 2007).

\section{CONCLUSIONS}

Double layers of wide vegetation belts $(300 \mathrm{~m})$ on mild slope $(1: 500)$ in the vertical direction with R. apiculata and C. equisetifolia exhibited a strong potential to decrease surge wave height and velocity reduction. However, flow velocity reduction was dominant compared with water depth reduction. Moreover, the offshoreward current velocities were significantly reduced compared to the landward 
current velocities on the mild slope due to the vegetation effect. For the same vegetation belt, typical slope (1:100) found more suitable for flow velocity reduction where as mild slope (1:500) for wave height reduction. Wide coastal vegetation belt with mild slope might be suitable for storm surge energy reduction; however, a doubling or tripling of forest width (from $100 \mathrm{~m}$ to $200 \mathrm{~m}$ or $300 \mathrm{~m}$ ) did not produce two-fold or three-fold increase of wave reduction with negligible additional velocity reduction.

Although vegetation density places an important role to reduce storm surge energy but for the same vegetation density the wave energy reduction by $R$. apiculata was not increased significantly compared to the $C$. equisetifolia. But young densely $C$. equisetifolia found more effective to reduce storm surge energy.

Although the simulations are conducted under limited conditions, the findings in this study can help the planners and designers in future coastal landscape planning, rehabilitation and coastal resource management.

This study considered the coastal vegetation effect for reducing storm surge damage using modified one-dimensional depth-averaged non-linear long wave differential equations. Wave height $(3.5 \mathrm{~m})$, long wave ( 2 hours) and short wave ( 2 minutes) were kept constant so that the run-up height at coast becomes similar of that observed at cyclone Sidr2007 in Bangladesh. Information used, especially tree characteristics and land topography in the study was drown only limited filed observations after Sidr2007 in Bangladesh and secondary sources. In addition, the water depth and flow velocity were discussed mainly in the present study. However, the storm surge forces and breaking moments which are more directly related with possible damages. In order to design an effective landscape with coastal vegetation, more study is needed on a wide range of cyclonic storm surge conditions, coastal topography and forest characteristics. Another important problem is scouring around the vegetation. The above problems together with validation of the numerical model against field data are the subjects of the future studies.

\section{ACKNOWLEDGMENTS}

The study was carried out while S.C. Das was doing research under the Japan Society for the Promotion of Science (JSPS) postdoctoral fellowship for foreigner researchers' programme. This research was supported by the JSPS grant in aid for the scientific research $(21 \cdot 09081)$.

\section{REFERENCES}

Danielsen F., Sorensen, M.K., Olwig, M.F., Selvam, V., Parish. F., Burgess, N.D., Hiraishi, T., Karunagaran, V.M., Rasmussen, M.S., Hansen, L.B., Quarto, A., Suryadiputra, N. 2005. The Asian tsunami: a protective role for coastal vegetation, Science 320(5748), $643 \mathrm{pp}$.

Food and Agriculture Organization (FAO) of the United Nations Regional Office for Asia and the Pacific. 2007. Coastal protection in the aftermath of the Indian Ocean tsunami: What role for the forests and trees? Proceedings of the Regional Technical Workshop, Khao Lak, Thailand, 28-31 August 2006.

Harada, K., and Imamura, F. 2006. Effects of coastal forest on tsunami hazard mitigation-a preliminary investigation, In: Tsunamis: case studies and recent developments, Advances in Natural and Technological Hazards Research, Berlin, Springer, 279-292.

Hiraishi, T., and Harada, K. 2003. Greenbelt Tsunami Prevention in South-Pacific Region, Report of the Port and Airport Research Institute, 42 (2), 1-20.

Investigation Team of Japan Society of Civil Engineering. 2008. Investigation report on the storm surge disaster by cyclone Sidr2007, Bangladesh (http://www.jsce.or.jp/report/46/index.shtml).

Kabir, M.M., Ahmed, M.M.Z., Azam, M.H., and Jakobsen, F. 2006. Effects of afforestation on strom surge propagation: a mathematical model study, Institute of water modelling (http://www.iwmbd.org/html/PUBS/publications/P015.PDF).

Karim, M.F., and Mimura, N. 2008. Impact of climate change and sea-level rise on cyclonic storm surge floods in Bangladesh, Global Environmental Change, 18, 490-500.

Mascarenhas, A., and Jayakumar, S. 2008. An environmental perspective of the post-tsunami scenario along the coast of Tamil Nadu, India: Role of sand dunes and forests, Journal of Environmental Management, 89, 24-34.

Massel, S.R., Furakawa, K., and Brinkman, R.M. 1999. Surface wave propagation in mangrove forests. Fluid Dynamics Research, 24, 219-249.

Mazda, Y., Magi, M., Ikeda, Y., Kurokawa, T, and Asano, T. 2006. Wave reduction in a mangrove forest dominated by Sonneratia sp., Wetland Ecology and Management, 14, 365-378. 
Ministry of Transport, Japan. 1996. Prediction of storm surge in Tokyo Bay, The second district port consortium bureau, 191pp. (in Japanese).

Murty, T.D, and Neralla, V.R. 1992. On the recurvature of tropical cyclones and the storm surge problem in Bangladesh, Natural Hazards, 6, 275-279.

Nandasana, N.A.K, Tanaka, N., and Tanimoto, K. 2008. Tsunami current inundation of ground with coastal vegetation effects; an initial step towards a natural solution for tsunami amelioration, Journal of earthquake and tsunami, 2, 157-171.

Paul, B.K. 2009. Why relatively fewer people died? The case of Bangladesh's cyclone Sidr, Natural Hazards, 50, 289-304.

Shuto, N. 1987. The effectiveness and limit of tsunami control forests. Coast Eng Jpn, 30(1), 143-153.

Tanaka, N., Sasaki, Y., Mowjood, M.I.M., Jinadasa, K.B.S.N., and Homchuen, S. 2007. Coastal vegetation structures and their functions in tsunami protection: Experience of the recent Indian Ocean tsunami, Landscape and Ecological Engineering, 3, 33-45.

Tanaka, N., Nandasena, N.A.K., Jinadasa, K.B.S.N., Sasaki, Y., Tanimoto, K., and Mowjood, M.I.M. 2009. Developing effective vegetation bioshield for tsunami protection, Journal of Civil and Environmental Engineering Systems, 26, 163-180.

Tanimoto, K., Tanaka, N., Nandasena, N.A.K., Iimura, K., and Shimizu T. 2007. Numerical simulation of tsunami prevention by coastal forest with several species of tropical tree (Japanese with English abstract), Annual Journal of Coastal Engineering, JSCE, 54, 1381-1385.

Thuy, N.B., Tanimoto, K., Tanaka, N., Harada K., Iimura, K. 2009. Effect of Open Gap in Coastal Forest on Tsunami Run-up - Investigations by Experiment and Numerical Simulation, Ocean Engineering, 36, 1258-1269.

Yanagisawa, H., Koshimura, S., Goto, K., Miyagi, T., Imamura, F., Ruangrassamee, A., and Tanavud, C. 2009. The reduction effects of mangrove forest on a tsunami based on field surveys at Pakarang Cape, Thailand and numerical analysis, Estuarine, Coastal and Shelf Science, 81, 27-37. 